\title{
Megabacteriose aviária: breve revisão
}

\author{
A vian megabacteriosis: brief review \\ Megabacteriosis aviar: breve reseña
}

Recebido: 27/12/2021 | Revisado: 02/01/2022 | Aceito: 03/01/2022 | Publicado: 04/01/2022

Cristiane Santana Silva

ORCID: https://orcid.org/0000-0003-3289-2077

Universidade Cruzeiro do Sul, Brasil

E-mail: cristianessvet@gmail.com

Maria Anete Lallo

ORCID: https://orcid.org/0000-0003-3578-3087

Universidade Paulista, Brasil

E-mail: anetelallo@hotmail.com

Henri Donnarumma Levy Bentubo

ORCID: https://orcid.org/0000-0003-0091-2504

Universidade Paulista, Brasil

Universidade do Vale do Paraíba, Brasil

E-mail: hbentubo@yahoo.com.br

\begin{abstract}
Resumo
Megabacteriose constitui designação genérica aplicada a uma importante doença infecciosa aviária, inicialmente diagnosticada em periquitos, canários e avestruzes, mas que nos últimos anos tem sido observada em outras espécies, como mamíferos. Apesar dos esforços da ciência, a classificação taxonômica do microrganismo causador da desordem ainda não está bem estabelecida. A existência de indivíduos assintomáticos sugere que os reservatórios naturais desempenham um importante papel na disseminação da infecção e contribui para a controvérsia a respeito do papel do microrganismo como um patógeno primário. Inúmeras técnicas têm sido experimentalmente testadas no sentido de produzir maior sensibilidade e especificidade para o diagnóstico da doença. Embora a proventriculite não seja exclusivamente causada por Macrorhabdus ornithogaster, ela costuma ser o sinal clínico mais comumente associado à megabacteriose. Aparentemente, os macrolídeos poliênicos tem sido empregados com sucesso no tratamento da doença. Contudo, novos estudos devem ser estimulados para que esses aspectos sejam devidamente esclarecidos promovendo, assim, consenso entre clínicos e laboratórios.
\end{abstract}

Palavras-chave: Megabacteriose; Macrorhabdus ornithogaster; Doenças das aves; Proventriculite.

\begin{abstract}
Megabacteriosis is the general designation for an important avian infectious disease that was first diagnosed in budgerigars, canaries and ostriches but in the recent years, the syndrome has been found in other species, including mammals. Despite the science efforts, the taxonomic classification of the microorganism that causes the disorder is still not well established. The existence of assymptomatic subjects suggest that the natural reservoir plays an important role on the widespread of the infection and contribute to the controversial aspects related to the agent's role as primary pathogen. Several techniques have been experimentally tested to produce more sensibility and specificity on the diagnostic of the ill. Although the proventriculitis is not only caused by Macrorhabdus ornithogaster, it is the most common clinical expression associated with megabacteriosis. Apparently, the polyenes macrolides have been successfully used to the treatment of the ill. However, new studies must be stimulated to properly elucidation of these aspects promoting considerable consensus between clinicians and the laboratories.
\end{abstract}

Keywords: Megabacteriosis; Macrorhabdus ornithogaster; Avian diseases; Proventriculitis.

\section{Resumen}

Megabacteriosis es una denominación genérica aplicada a una importante enfermedad infecciosa aviar, diagnosticada inicialmente en periquitos, canarios y avestruces, pero que en los últimos años se ha observado en otras especies, como los mamíferos. A pesar de los esfuerzos de la ciencia, la clasificación taxonómica del microorganismo causante del trastorno aún no está bien establecida. La existencia de individuos asintomáticos sugiere que los reservorios naturales juegan un papel importante en la propagación de la infección y contribuye a la controversia sobre el papel del microorganismo como patógeno primario. Varias técnicas se han probado experimentalmente con el fin de producir una mayor sensibilidad y especificidad para el diagnóstico de la enfermedad. Aunque la proventriculitis no es causada exclusivamente por macrorhabdus ornithogaster, a menudo es el signo clínico más comúnmente asociado con megabacteriosis. Aparentemente, los macrólidos poliénicos se han utilizado con éxito en el tratamiento de la enfermedad. Sin embargo, conviene fomentar la realización de estudios adicionales para que estos aspectos se aclaren adecuadamente, promoviendo así un consenso entre clínicos y laboratorios.

Palabras clave: Megabacteriosis; Macrorhabdus ornithogaster; Enfermedades de las aves; Proventriculitis. 


\section{Introdução}

O médico veterinário enfrenta um grande desafio a cada novo caso, especialmente na clínica de aves. Esses animais tão peculiares não apenas desempenham papel fundamental dentro dos sistemas produtivos de alimentação humana e animal, como também ornamentam parques, praças e casas, despertando estima e afeição por parte de seus observadores (De Andrade, $1997 \&$ Hofling \& Camargo, 2002). Desde a antiguidade, as aves compartilham com os seres humanos os recursos do planeta no qual vivem. A simbologia das aves para a humanidade é reconhecida há milênios; pinturas pré-históricas datadas de 25.000 A. C. têm sido encontradas em escavações arqueológicas. No ano de 3.000 A. C, o símbolo de uma águia era venerado na mesopotâmia; nesse mesmo período, no Egito, a cabeça de um falcão representava Horus, um deus celestial para essa civilização. No entanto, algumas espécies desses animais são, por vezes, consideradas símbolos de mau-agouro pelo ocidente, como é o caso dos corvos, abutres e urubus (De Andrade, 1997).

Existem no mundo, aproximadamente 9.900 espécies diferentes de aves, sendo que a maioria delas pode ser encontrada na América do Sul e Central (De Andrade, 1997). Segundo o Ministério do Meio Ambiente (MMA), o Brasil possui 1.696 espécies descritas e registradas na lista do Comitê Brasileiro de Registro Ornitológico (CBRO), ocupando o terceiro lugar no mundo em diversidade de aves (MMA, 2020). Dados da União Brasileira de Avicultura (UBA) demonstram que a avicultura brasileira é responsável por 1,5\% do produto interno bruto (PIB), é capaz de gerar 4,8 milhões de empregos diretos e indiretos e arrecadar mais de $\mathrm{R} \$ 6$ bilhões em impostos anualmente (UBA, 2019).

As aves constituem valiosa fonte nutritiva para a civilização humana. Estimativas da UBA (2019) informam que o Brasil abateu para consumo 4.370.086 cabeças de frango de corte e produziu 2.159.277 dúzias de ovos, até o quarto trimestre de 2007, ano de produção recorde no país. Do total de carne de frango produzida no Brasil, aproximadamente, $70 \%$ foi destinada ao mercado consumidor interno e, atualmente, o consumo equivale a $38 \mathrm{~kg} / \mathrm{habitante} / \mathrm{ano}$. Os outros $30 \%$ são destinados à cerca de 150 países, diz a Associação Brasileira dos Exportadores de Frango, atualmente, coligada à União Brasileira de Avicultura (UBA-Abef) (UBA-Abef, 2019). No primeiro semestre de 2008 as exportações de carne de frango totalizaram 1,8 milhões de toneladas, representando um aumento de 19\% em relação ao mesmo período de 2007 (UBA-Abef, 2019). Os estados de Santa Catarina, Paraná, São Paulo e Minas Gerais foram responsáveis por 75,76\% das exportações em 2002 (Mendes et al, 2004).

Segundo o Instituto Brasileiro do Meio Ambiente e dos Recursos Naturais Renováveis (IBAMA), a criação de aves silvestres e exóticas no brasil, para finalidade conservacionista ou para produção comercial, vem crescendo consideravelmente nos últimos anos (IBAMA, 2021). Em virtude do alto potencial reprodutivo, adaptabilidade, produtos e subprodutos, destacamse as criações de avestruz (strutio camelus) e emas (rhea americana) (Silva, 2007). Segundo a Associação de Avicultura Industrial (AAI), a principal região criadora de avestruzes em 2004 foi São Paulo, com um plantel equivalente a 56 mil cabeças. No ano seguinte, o plantel brasileiro chegou a 200 mil aves, sendo que 70 mil estavam concentradas no estado de São Paulo (AAI, 2016). No ano de 2006, já existiam 317 criadouros legalizados de aves silvestres no Brasil e 111 deles localizados apenas no estado de São Paulo (IBAMA, 2021).

Os subprodutos, como as penas, são utilizadas como abrigo em clima frio, e seus excrementos são usados como adubo orgânico em jardins, hortas e pomares (De Andrade, 1997). Esses mesmos elementos provenientes da fauna avícola já foram utilizados na cabeça e em outras partes do corpo por povos indígenas em suas canções, rituais religiosos, danças e artesanato. Ainda hoje, penas de pavão, plumas de avestruz e outros desses subprodutos ainda são utilizados, por exemplo, no carnaval, rito folclórico tradicionalmente praticado no Brasil e outras localidades do mundo, movimentando direta ou indiretamente, milhões de dólares (UBA, 2019). Apesar dos recentes avanços da Medicina Veterinária, possuir uma ave ornamental de valor econômico e emocional elevados constitui preocupação considerável para alguns proprietários, que ainda têm dificuldades em encontrar médicos veterinários tecnicamente preparados para o pronto-atendimento desses animais. Tal fato tem sido atribuído 
à grande maioria das clínicas especializadas em animais de estimação não estar preparada para atender aves (Aguilar et al, 2005).

As aves podem ser reservatórios de inúmeros agentes etiológicos de doenças importantes para o homem e para os animais, como Salmonella spp., Escherichia coli, Influenza spp., Aspergillus spp., entre outros (Assis \& Santos, 2001, Lima et al, 2001, Silva \& Duarte, 2002, Ibiapina et al, 2005). Alguns desses agentes patogênicos são oportunistas, ou seja, convivem bem com seus hospedeiros até que um elemento de imunocomprometimento do hospedeiro permita sua multiplicação e, consequentemente, lhes causem danos orgânicos irreparáveis. Isso se torna especialmente relevante quando aves silvestres ou exóticas são misturadas com outras, sem período de quarentena, por exemplo; ou quando nos referimos às aves provenientes do tráfico, mais predispostas a apresentar seu sistema imunológico deficitário devido ao estresse causado pelo estresse da captura e transporte inadequados (Nascimento \& Alves, 2007). Fatores como antibióticoterapia prolongada, doenças imunossupressoras de base, deficiências nutricionais e senilidade também constituem fatores predisponentes que podem estar associados a infecções oportunísticas, muitas vezes, capazes de causar grandes perdas econômicas. O manejo inadequado se caracteriza como um dos principais fatores predisponentes que podem estar associados à ocorrência de doenças em aves domésticas (Aguilar et al, 2005).

\section{Objetivos e Metodologia}

O objetivo do presente trabalho de revisão narrativa da literatura foi desenvolver um estudo abrangente, discutindo os aspectos clínicos e laboratoriais da megabacteriose aviária, considerados ainda polêmicos na literatura, uma vez que as definições de etiologia, epidemiologia, diagnóstico e tratamento ainda são alvos de controvérsia na literatura veterinária. Para tanto, foram admitidos os seguintes unitermos: "doenças das aves", "proventriculite", "megabacteriose" e, "Macrorhabdus ornithogaster", em língua portuguesa e língua inglesa. No levantamento bibliográfico, foram consultadas as seguintes bases de dados de acesso livre: Google acadêmico, Lilacs, Scielo e Pubmed-Medline, disponíveis na rede mundial de computadores. Em virtude do número limitado de trabalhos de pesquisa relacionados ao assunto, foram considerados pertinentes a essa revisão todos aqueles artigos publicados entre os anos 2000 e 2020. A seleção dos artigos foi arbitrária, de acordo com o ponto de vista e contexto do tema abordado, sendo escolhidos aqueles que tratavam, especificamente, de casos de enfermidade aviária, com envolvimento de inglúvio e pró-ventrículo, cuja etiologia tenha sido associada ao Macrorhabdus ornithogaster, agente etiológico da megabacteriose aviária (Moreira, 2004, UNESP, 2015, Ferenhof \& Fernandes, 2016 \& Gonçalves, 2019). Considerando as características inerentes à revisão narrativa, não se desenvolveu aqui o estudo com base em uma questão norteadora específica, mas em um tema amplo, portanto, a seleção da fonte de informações não se baseou em uma estratégia sistematizada, mas sim em publicações gerais sobre o assunto, proporcionando ao leitor informação sobre um determinado tema em um limitado espaço de tempo (Cambuí \& Natali, 2015).

\section{Megabacteriose}

Para alguns autores, trata-se de uma doença de caráter crônico que produz debilidade progressiva e, consequentemente, a morte de várias espécies de aves, incluindo frangos comerciais (Phalen \& Moore, 2003 \& Flôres et al, 2005, Bruno, 2016). No entanto, ainda existem dúvidas a respeito do tempo de evolução da doença, que em alguns casos pode provocar a morte dos animais acometidos em poucas semanas, sugerindo que a enfermidade apresente quadros infecciosos agudos (Segabinazi et al, 2004). Os primeiros relatos de megabacteriose no mundo surgiram na década de 1980, quando a doença foi diagnosticada em periquitos australianos (Melopsittacus undulatus). A partir daí inúmeros novos relatos surgiram, chamando a atenção da comunidade veterinária para a gravidade que essa enfermidade pode apresentar e ampla variedade de 
espécies que podem ser acometidas (Gerlach, 2001). Estudo realizado na Inglaterra constatou que a megabacteriose foi a maior causa de morbidade e mortalidade em periquitos australianos entre os anos 1987 e 1995 (Flôres at al, 2005).

A doença foi descrita pela primeira vez no Brasil por Werther et al (2000), quando a megabactéria foi encontrada no exame pós-morte de canários (Serinus canaria), agapornis (Agapornis spp.) e periquitos (M. undulatus) provenientes da região de Ribeirão Preto, estado de São Paulo (Werther et al, 2000). Após esse achado, a doença foi descrita em canários belgas (Serinus canaria domestica), emas (Rhea americana) e avestruzes (Struthio camelus) e calopsitas (Nymphicus hollandicus) (Segabinazi et al, 2004, Flôres, at al, 2005, Martins et al, 2006, Bruno, 2016, De Araujo Cavalcante Filho et al, 2017 \& Moreira, 2019). Evidências científicas, como aquelas observadas na Alemanha, onde a infecção foi verificada em galinhas poedeiras e reprodutores de diferentes lotes sugerem que a megabacteriose está amplamente distribuída entre a população de aves domésticas e poderia ser causa de perdas econômicas significativas para avicultura industrial (Phalen \& Moore, 2003 \& Martins et al, 2006). Por isso, alguns autores salientam a necessidade da realização de investigações e controle sobre a presença de megabactérias não apenas nas criações domésticas, mas também em criações avícolas de escala industrial (Flôres at al, 2005 \& Moreira, 2019).

Casos de infecção por megabactéria em tantas outras espécies têm sido diagnosticados em serviços de atendimento de aves atentos para a ocorrência dessa doença, como é o caso do ambulatório da Escola de Veterinária da Universidade Federal de Minas Gerais (UFMG) localizada na cidade de Belo Horizonte (MG), Brasil (Martins et al, 2006). Segundo Martins et al (2006), muito a respeito do desconhecimento sobre a real situação da megabacteriose no Brasil se deve ao fato de muitos proprietários ainda não recorrerem a atendimento clínico especializado e a falta de atenção da maioria dos profissionais para a ocorrência da doença em nosso meio.

\subsection{Etiologia}

A classificação taxonômica da "megabactéria" ainda é controversa. A princípio, ela foi considerada uma levedura (Dorrestein et al, 1980), contudo, a semelhança morfológica com um bacilo procariótico e a característica basofílica apresentada na coloração de Gram fizeram com que o microrganismo causador da megabacteriose passasse a ser considerado uma bactéria (Van Herck et al, 1984, Revolledo \& Piantini-Ferreira, 2009). De fato, as considerações taxonômicas inicialmente estabelecidas são aceitáveis se levarmos em conta a tendência dos achados da época e a relativa dificuldade e restrições que existem em se caracterizar a presença de organelas citoplasmáticas e componentes nucleares (Scanlan \& Graham, 1990, Harrison \& Lightfoot, 2006).

$\mathrm{O}$ tamanho bastante superior àquele observado na maioria dos microrganismos procarióticos sempre preocupou os pesquisadores quanto à certeza em relação à classificação taxonômica desse microrganismo. Uma bactéria compreende medidas que variam de 1-5 $\mu \mathrm{m}$, enquanto a "megabactéria" pode alcançar dimensões tão grandes quanto 1-5 $\mu \mathrm{m}$ apenas na largura, enquanto seu comprimento pode chegar a 20-90 $\mu \mathrm{m}$, in vivo (Segabinazi et al, 2004, Martins et al, 2006 \& Silva, 2007). Achados laboratoriais recentes, afirmam que as tradicionais formas grandes, abundantemente observadas em preparações de exame direto, se tornam reduzidas quando o microrganismo é submetido a crescimento em meios de cultura artificiais. Portanto, aferir medições nessas duas condições pode evidenciar diferenças significativas. Esse fato deve ser levado em conta em futuros estudos morfométricos evitando assim equívocos e polêmica desnecessária (Martins et al., 2006).

Estudo realizado por Thomaszewski et al (2003), demonstrou a presença de estruturas similares a núcleos, caracterizando a "megabactéria" como um eucarioto, o que definitivamente derruba a teoria de o microrganismo ser uma bactéria. Adicionalmente, estudos ultraestruturais demonstraram a existência de três camadas distintas, compostas por celulose e quitina, que recobrem a membrana celular da célula, semelhante à parede celular dos fungos (Gerlach, 2001, Lacaz et al, 2002, \& Thomaszewski et al, 2003). Através da análise filogenética, os pesquisadores confirmaram a relação de proximidade 
que a "megabactéria" possui com o reino fungi. O estudo das sequências $18 \mathrm{~S}$ e $26 \mathrm{~S}$ (domínios d1/d2) do DNA ribossomal por técnica de reação em cadeia da polimerase (PCR), identificaram a megabactéria como sendo a forma anamórfica de um fungo ascomiceto leveduriforme, o que retoma a teoria de Dorrestein et al (1980).

A denominação Macrorhabdus ornithogaster foi proposta para esse novo gênero e nova espécie de microrganismo. A partir dessa nova proposta de classificação taxonômica, a comunidade científica levantou a hipótese sobre a necessidade de uma mudança na designação da doença, sugerindo que o termo consagrado "megabacteriose", considerado inadequado, fosse alterado para "macrorhabidose". Se considerarmos que a "megabacteriose" é uma micose e que os sufixos "ose" ou "micose" compõem o nome da maior parte das doenças estudadas na micologia, tanto a designação "macrorhabidose" como “macrorhabidomicose" estariam corretas (Lacaz et al, 2002, Thomaszewski et al, 2003, Speer et al, 2004 \& Bruno, 2016).

Apesar dos estudos mais modernos apontarem na direção do reino fungi, a ocorrência de equívocos taxonômicos deve ser considerada, pois não seria a primeira vez que isso ocorreria com um microrganismo estudado em micologia, como por exemplo, Pythium incidiosum, que já foi considerado fungo e protozoário e, atualmente, está classificado num reino à parte denominado Straminopila (Shenep et al, 1998). Martins et al (2006) sugerem em seu trabalho que M. ornithogaster é um microrganismo móvel. Esse achado constitui informação relevante, uma vez que, esse tipo de característica não é comum em fungos. Os autores atribuem essa capacidade à possível presença de uma organela polar ou um flagelo que permite movimentos de rotação nas formas pequenas; e à observação de pequenas saliências laterais que contribuem para movimentos lineares discretos de torção nas células maiores. É imperativo que novos estudos sobre as organelas envolvidas com a motilidade sejam realizados no intuito de esclarecer supostos enganos relacionados com classificação taxonômica de M. ornithogaster (Martins et al, 2006).

A presença concomitante de $M$. ornithogaster e bactérias reconhecidamente patogênicas como E. coli traz à tona discussões a cerca da atribuição da megabacteriose ao M. ornithogaster. Características relacionadas com a sensibilidade de $M$. ornithogaster aos antimicrobianos ainda são bem pouco conhecidas. Testes de sensibilidade frente a antibióticos realizados com isolados de M. ornithogaster, obtidos em 1990, sugerem que a sensibilidade do agente pode ser menor in vitro do que in vivo. Uma vez que o isolamento desse agente é pouco frequente e que a real situação taxonômica do microrganismo ainda é alvo de discussão, a realização de testes in vivo e in vitro que tenham como objetivo determinar a sensibilidade ou resistência de M. ornithogaster aos antimicrobianos, bem como, a determinação das concentrações inibitórias mínimas (CIM) deve ser estimulada para que possam ser estabelecidos esses parâmetros (Phalen, 2005).

\subsection{Epidemiologia}

A megabacteriose, doença "não-zoonótica" importante em aves de cativeiro, tem sido cada vez mais estudada em todo o mundo. As descrições contemplam inúmeras espécies como: agapornis (Agapornis spp.), avestruz (Struthio camelus), canário (Serinus canarius), cacatuas (Cacatua galerita), ema (Rhea americana), frango doméstico (Gallus gallus), mandarin (Taeniopygia guttata), perdiz (Alectoris rufa), periquito (Melopsittacus undulatus), peru (Alectura lathami), pombo (Columba livia), rolinha (Columbina talpacoti e C. livia), tucano (Tucano toco) e até alguns mamíferos (Simpsom, 1992, Baker, 1992, Huchzermeyer et al, 1993, Tonelli, 1993, Filippich \& Hendrikz, 1998, Cook, 2000, Huchzermeyer \& Henton, 2000, Gerlach, 2001, Scullion \& Scullion, 2004; Flôres et al, 2005, Marlier et al, 2006, Martins et al, 2006 \& Robino et al, 2019).

Embora se saiba que M. ornithogaster seja um patógeno universal em avicultura, a doença é especialmente relatada em periquitos e canários. A preferência do agente por esses gêneros de psitacídios e passeiriformes não está comprovada. Uma hipótese para essa aparente prevalência talvez seja a popularidade que essas espécies domésticas têm na sociedade, e por isso, a dedicação da comunidade científica aos estudos relacionados com essas espécies (Filippch \& Hendrikz, 1998, Flôres et al, 2005 \& Marlier et al, 2006). Estudo realizado por Filippich e Hendrikz (1998) encontrou diferença significativa em relação ao 
sexo na prevalência de $M$. ornithogaster nas fezes de periquitos, com relativa predominância do microrganismo nos machos. Segundo esses mesmos autores a idade não é um fator relevante para a prevalência de M. ornithogaster nas fezes daqueles animais.

O microrganismo ( $M$. ornithogaster) pode ser detectado em aves com aspecto clínico normal, caracterizando as mesmas como reservatórios naturais do agente. Assim como ocorre com as aves doentes, aquelas aves portadoras assintomáticas são fontes de infecção para outros indivíduos sadios predispostos à colonização e infecção. Os índices de mortalidade podem apresentar amplas variações (12,5\% e 100\%) dependendo do estado clínico das aves e do grau de evolução da doença (Filippich, 2004, Phalen, 2005, Flôres et al, 2005 \& Martins et al, 2006). Marinho et al (2004), relataram a que o trato gastrintestinal de avestruzes, por exemplo, é colonizado por leveduras potencialmente patogênicas como Candida spp. e Cryptococcus spp.

A variedade de espécies que coabitam nos mais diversos ambientes, ainda mais em criações domésticas fundamenta a teoria da ocorrência de transmissão interespecífica, que é facilitada pelas políticas convencionais de biossegurança adotadas nessas criações (Gottdenker et al, 2005). Macrorhabidus ornithogaster pode ser isolado da mucosa de pró-ventrículo e fezes, principalmente, por isso, alimentos regurgitados e excrementos de aves portadoras do agente infeccioso caracterizam a via oral como a principal rota de transmissão horizontal (porta de entrada) de M. ornithogaster para os susceptíveis (Martins et al, 2006). Estudos experimentais realizados em periquitos sugerem que a transmissão vertical (mãe-filhote) não representa uma via de transmissão importante para essa doença. No entanto, os autores recomendam que, por prevenção, os ovos sejam retirados dos ninhos de periquitos adultos em plantéis onde o microrganismo já foi detectado; e incubados artificialmente, evitando a exposição do filhote (Moore et al, 2001).

O papel do agente como patógeno primário, tem sido alvo de discussão. Seria a megabacteriose uma enfermidade tão independente, cuja patogênese não necessite de fatores predisponentes? Todas as doenças infecciosas necessitam de algum fator predisponente. A ocorrência de casos isolados ou surtos de megabacteriose em populações aviárias está bastante relacionado a doenças de base de caráter imunocomprometedor, como é o caso do estresse, por exemplo. Pennycott et al (2003) relataram a ocorrência simultânea de doença de Marek, candidíase e megabacteriose em galinhas domésticas (Gallus gallus) e codornas japonesas (Coturnix coturnix japonica) (Pennycott et al, 2003 \& Jansson et al, 2008).

Relatos um pouco mais recentes do que aqueles originais indicam que M. ornithogaster pode também acometer mamíferos. Grande número de microrganismos foi obtido de nariz de um filhote de gato e em lavado bronco alveolar de um poodle de dois anos de idade (Cook, 2000). Estudo experimental realizado em camundongos (Mus musculus) evidenciou 100\% de mortalidade, com lesões hepáticas importantes nesses animais (Martins et al, 2006). Achados como esses relatados por Cook (2000) e Martins et al (2006) ilustram a capacidade de M. ornithogaster em colonizar, infectar e causar lesão também em mamíferos. Dessa forma, dada a realidade atual da relação próxima entre tutor e animal de estimação, não se pode descartar a possibilidade de seres humanos que têm contato próximo e promíscuo com aves serem colonizados e, eventualmente, desenvolverem a doença. $\mathrm{O}$ fato da constituição química do muco (proteína coilina) presente no sistema respiratório superior dos mamíferos ser similar à das aves, poderia sustentar essa hipótese (Huchzermeyer \& Henton, 2000 \& Son et al, 2004).

\subsection{Manifestações Clínicas}

Os animais acometidos por megabacteriose (M. ornithogaster) podem ou não apresentar sinais da infecção (Phalen \& Moore, 2003). Quando manifestados, esses sinais são referidos como "síndrome light going" por alguns autores, porém, as características dessa síndrome não ficam expressamente esclarecidas (De Queirós et al., 2011 \& De Araújo Cavalcante Filho et al, 2017). A expressão e especificidade desses sinais são muito variáveis, não sendo patognomônicos e podem confundir proprietários e clínicos, que devem estar atentos para a condição clínica da ave no transcorrer da infecção e estágio da doença, 
que podem ser fatores determinantes da expressão de sinais clínicos mais brandos ou mais marcados (Phalen, 2005 \& Jansson et al, 2008). Sinais clínicos inespecíficos tais como: apatia, fraqueza, atrofia muscular, penas arrepiadas e hipotermia são associados aos estágios iniciais da megabacteriose (Christensen et al, 1997, Segabinazi et al, 2004, Fillipich, 2004, Flôres et al, 2005 \& Martins et al, 2006).

A proventriculite é o quadro clínico mais comumente associado à doença e tem sido descrita em periquitos (Melopsittacus undulatus), canários (Serinus canarius) e avestruzes (Struthio camelus) (Simpsom, 1992, Baker, 1992, Huchzermeyer et al, 1993, Tonelli, 1993, Filippich \& Hendrikz, 1998, Scullion \& Scullion, 2004, Flôres et al, 2005, Marlier et al, 2006 \& Martins et al, 2006). Os sinais relacionados ao sistema digestório são os mais marcados e podem se expressar por disfagia, regurgitação intermitente, aparente polifagia associada a emagrecimento progressivo e consequente estado de caquexia, diminuição da conversão alimentar e diarreia com frequente acúmulo de fezes na cloaca (Baker, 1992, Phalen \& Moore, 2003, Segabinazi et al, 2004, Speer et al, 2004, Flôres et al, 2005 \& Martins et al., 2006).

Déficit respiratório e neurológico, representados por dispneia e incoordenação motora, respectivamente, também podem ser observados nas aves acometidas e são associados à degenerada condição clínica na qual se encontram as aves nos estágios mais avançados da doença. A maior parte dos animais acometidos pela doença, especialmente aqueles que apresentam maior debilidade, têm a morte como desfecho de seus casos (Baker, 1992, Segabinazi et al, 2004, Flôres et al, 2005 \& Martins et al, 2006).

\subsection{Diagnóstico}

Assim como a classificação taxonômica do agente e seu papel como patógeno primário, também o diagnóstico da megabacteriose é alvo de bastante controvérsia. Matéria vegetal ou artefatos técnicos podem ser considerados $M$. ornithogaster, equivocadamente. Além disso, o fato de algumas aves, aparentemente sintomáticas, apresentarem um número bastante reduzido de microrganismos nas fezes, frequentemente, prejudica o estabelecimento do diagnóstico. Assim, a experiência do técnico que realiza os exames influencia na sensibilidade do diagnóstico (Speer et al, 2004).

Em virtude do rápido avanço que a doença pode apresentar, na maioria dos casos, o diagnóstico definitivo da megabacteriose só é estabelecido ao exame pós-morte do animal. Por isso, a necessidade da aplicação de técnicas diagnósticas mais sensíveis, capazes de detectar precocemente a infecção. Na prática, o diagnóstico clínico deve ser baseado no emprego de metodologia clássica, isto é, levando-se em conta os achados obtidos a partir do histórico clinico, exame físico e exame laboratorial. Contudo, a padronização de técnicas de biologia molecular constitui numa saída para o diagnóstico definitivo da doença (Speer et al, 2004 \& Phalen, 2005).

\subsubsection{Clínico}

Basear-se apenas na detecção de sinais clínicos ou na presença de $M$. ornithogaster por exame direto de amostras clínicas constitui procedimento que deve ser desencorajado. Exames hematológicos e bioquímicos também constituem ferramentas pouco específicas. O hemograma pode revelar anemia, enquanto o leucograma, leucocitose com linfocitose, monocitose, basofilia e trombocitose. Exames bioquímicos expressam decréscimo acentuado das concentrações de eletrólitos (Henderson et al, 1988 \& Son et al, 2004).

A avaliação criteriosa e cautelosa dessas duas variáveis e o encaminhamento de amostras clínicas adequadas para confirmação laboratorial devem ser condutas adotadas pelo clínico no ambulatório de aves. É sempre imperativo que o clínico esteja atento para a ocorrência da doença e que, por vezes, algumas aves podem ser assintomáticas e é necessário diferenciar os sintomas da megabacteriose de outras doenças concomitantes (Pennycott et al, 2003 \& Speer et al, 2004). 
Adicionalmente, apesar de pouco empregada, a radiografia contrastada (sulfato de bário) pode revelar a retração das paredes da região de intersecção proventrículo e ventrículo, o que, segundo os autores, representa um forte indício diagnóstico de megabacteriose (Ritchie et al, 1997).

\subsubsection{Laboratorial}

O diagnóstico laboratorial da megabacteriose é ainda bastante incipiente, isto é, não está definitivamente estabelecido. No entanto, conforme se sucederem os trabalhos de pesquisa, mais se conhecerá sobre o agente patogênico, e assim novas metodologias serão propostas e empregadas na rotina. Nos dias atuais, o diagnóstico preditivo e/ou definitivo de megabacteriose é obtido através de exame direto (individual ou em massa), cultura microbiológica, exame necroscópico e histopatologia (Speer et al, 2004, Phalen, 2005, Martins et al, 2006 \& Baron et al, 2021).

\subsubsection{Exame Direto}

Existem dois métodos laboratoriais que podem ser aplicados ao exame direto para verificação de M. ornithogaster em aves doentes ou clinicamente assintomáticas: decalque da mucosa do pró-ventrículo em lâmina de vidro para microscopia (Cristensen et al, 1997, Segabinazi et al, 2004 \& Martins et al., 2006) e esfregaço de fezes (Segabinazi et al, 2004, Flôres et al., 2005 \& Martins et al, 2006). O decalque da mucosa pró-ventricular, indicado para aves que vieram ao óbito naturalmente ou eutanasiadas, deve ser realizado em lâmina de vidro limpa e seca, para melhor observação ao microscópio de luz (Cristensen et al., 1997, Speer et al, 2004, Segabinazi et al, $2004 \&$ Martins et al, 2006). O muco, em alguns casos, encontrado aderido à mucosa do pró-ventrículo, também pode ser material clínico empregado no exame direto. Em animais vivos, o conteúdo do pró-ventrículo pode ser obtido por lavado pró-ventricular, embora os autores ainda esbocem reserva quanto à sensibilidade do exame quando o material é coletado dessa forma (Segabinazi et al, 2004, Flôres et al, 2005 \& Marlier et al, 2006).

A presença de M. ornithogaster em plantéis sem sinais clínicos da doença pode ser determinada através da coleta de amostras de fezes frescas por pelo menos cinco dias consecutivos e posterior realização de esfregaços. No caso de animais doentes, o mesmo procedimento pode ser adotado. Ainda que várias coletas sejam realizadas é preciso considerar a possibilidade de não detectar o parasita nas preparações (Speer et al, 2004, Martins et al, 2006, Bruno, 2016). Segundo Speer et al (2006), a observação de exames direto, preparados com fezes frescas, ainda não fixados ou corados, permite melhor visualização de M. ornithogaster. Até o momento, as colorações rotineiramente aplicadas à coloração de M. ornithogaster são Gram, Giemsa, Wright, Leishman, Diff-quik e Calcofluor branco M2R (Segabinazi et al, 2004, Son et al, 2004, Speer et al, 2004, Flôres et al, 2005 \& Martins et al, 2006). A técnica de Gram é muito difundida em bacteriologia e permanece na rotina de identificação de $M$. ornithogaster como herança da época que esse microrganismos era considerado um procarionte. O fungo possui características basofílicas e se cora fracamente por essa técnica (Segabinazi et al, 2004, Flôres et al, 2005 \& Martins et al, 2006). As colorações de Giemsa e Calcofluor são menos empregadas, mas produzem resultados semelhantes àqueles obtidos pela técnica de Gram. O inconveniente da coloração com Calcofluor e que a leitura deve ser realizada em microscópio de fluorescência o que mediante os valores elevados desse investimento, inviabiliza se emprego na rotina (Speer et al, 2004 \& Martins et al, 2006).

Macrorhabdus ornithogaster habitualmente se apresenta em arranjo de paliçada em exames diretos de material proveniente de pró-ventrículo, como já foi observado em canários (Martins et al, 2006). Além disso, microrganismos encapsulados podem ser encontrados em decalque de fígado e baço de aves infectadas (Son et al, 2004). 


\subsubsection{Cultura}

Poucos autores têm se preocupado com os aspectos microbiológicos de caracterização do agente, que podem ser muito úteis para o diagnóstico da megabacteriose. A dificuldade de obtenção de M. ornithogaster em cultura tem contribuído significantemente para o atraso no conhecimento sobre esse novo agente infeccioso (Son et al, 2004). Macrorhabdus ornithogaster é considerado um fungo anaeróbio facultativo e fermentador (Martins et al, 2006 \& Silva, 2007). Experimentos conduzidos por Martins et al (2006) relataram que os isolados de M. ornithogaster expressaram crescimento mais exuberante quando incubados em estufa $37{ }^{\circ} \mathrm{C}$ com $5 \%$ de dióxido de carbono $\left(\mathrm{CO}_{2}\right)$. Ravelhofer-Rotheneder et al (2000) obtiveram crescimento M. ornithogaster em cultura semeando amostras provenientes de material clínico em meio mínimo (MM) acrescido de $20 \%$ de soro fetal bovino (SFB) e $5 \%$ de glicose. Outro pesquisador já relatou sucesso no isolamento do agente quando submetido a cultivo em meio MRS, tradicionalmente empregado para o cultivo de Lactobacillus spp. (Gerlach, 2001).

Segundo Martins et al (2006), a cultura de M. ornithogaster pode ser obtida por meio da semeadura de amostras provenientes de espécimes clínicos (vide diagnóstico) em meio sólido para fungos (ágar sabouraud dextrose [ASD]) e meio seletivo para fungos patogênicos. Embora não tenha sido especificado pelo autor, admiti-se que o segundo meio citado seja ASD acrescido de cloranfenicol $(0,5 \mathrm{~g} / \mathrm{l})$ e ciclo-heximida $(0,1 \mathrm{~g} / \mathrm{l})$, tradicionalmente empregado no laboratório de diagnóstico de infecções fúngicas (Lacaz et al., 2002). Ciclo-heximida é substância classicamente empregada em meios de cultura seletivos para fungos pela sua reconhecida capacidade de inibir o crescimento de fungos filamentosos. No entanto, se sabe que algumas espécies de fungos patogênicos, como Trichosporon cutaneum e T. inkin, também podem eventualmente ser inibidos por essa substância, comprometendo o diagnóstico. Portanto, esse dado é importante para esclarecer que M. ornithogaster não sofre inibição pela ciclo-heximida, apresentando crescimento satisfatório (De Hoog et al., 2000 \& Bentubo, 2008).

No entanto, estudo posterior avaliou o crescimento e capacidade de assimilação de carboidratos de M. ornithogaster sob diferentes condições, incluindo, tipo de meio, valor de ph, tensão de oxigênio e temperatura. Os autores afirmaram ter obtido condições ótimas de crescimento de M. ornithogaster quando o microrganismo foi semeado em meio de básico de Eagle acrescido de $20 \%$ de SFB e $5 \%$ de glicose, com ph entre 3 e 4 , temperatura de $42{ }^{\circ} \mathrm{C}$ e condição de microaerofilia (Hannafusa et al, 2007). A motilidade detectada nesse microrganismo pôde ser verificada quando cultivos obtidos em meio sólido de cultura foram sub-cultivados em meio líquido de tioglicolato (Martins et al, 2006).

\subsubsection{Necroscopia}

Em virtude dos altos índices de mortalidade, o exame pós-morte constitui a ferramenta mais empregada no diagnóstico definitivo da megabacteriose. Ao exame necroscópico é possível observar que aves acometidas por $M$. ornithogaster apresentam mucosa oral esbranquiçada e acometimento acentuado do pró-ventrículo (Segabinazi et al, 2004, Son et al, 2004 \& Martins et al, 2006). A palidez apresentada pela serosa e acentuada distensão são as primeiras alterações macroscópicas observadas no pró-ventrículo (Baker, 1992, Phalen \& Moore, 2003, Segabinazi et al, 2004, Flôres et al, 2005, Martins et al, 2006 \& Jansson et al, 2008). Hiperemia, hemorragia e ulceração da mucosa são evidentes no pró-ventrículo (Baker, 1992, Phalen \& Moore, 2003, Baker, 1992, Segabinazi et al, 2004, Martins et al, 2006 \& Jansson et al, 2008). A ruptura do pró-ventrículo e consequente infecção da cavidade celomática são incomuns, mas já relatados na literatura (Jansson et al, 2008).

A presença de muco viscoso aderido à mucosa e secreção leitosa podem, eventualmente, ser observadas no próventrículo, ressaltando-se a maior prevalência da primeira (Phalen \& Moore, 2003, Flôres et al, 2005, Martins et al, 2006 \& Jansson et al, 2008). Alimento mal digerido com coloração escurecida e hemorragia são comumente observados nos quadros de megabacteriose (Segabinazi et al, 2004 \& Flôres et al, 2005). Além disso, o acometimento hepático fica evidente pela 
observação de áreas amareladas e pontos de hemorragia (Flôres et al, 2005 \& Martins et al, 2006). A exaustão da gordura corporal e coronariana são identificadas como resultado da caquexia (Segabinazi et al., 2004).

\subsubsection{Histopatologia}

O comprometimento do revestimento de coilina na mucosa, decorrente da colonização da superfície do ventrículo por M. ornithogaster, é bem perceptível. Glândulas presentes na mucosa do ventrículo secretam complexos glicoprotéicos que se solidificam na superfície da mucosa, formando um tipo de cutícula protetora. Quando os microrganismos penetram a membrana coilina, promovem degeneração dessas glândulas, consequentemente, as lesões progridem e produzem atrofia e necrose da camada glandular com destruição da coilina, visualizada em cortes histológicos (Phalen \& Moore, 2003 \& Son et al, 2004).

Proventriculite subaguda a crônica com infiltrado linfoplasmocitário fica evidenciada através do exame microscópico do tecido acometido (Flôres et al, $2005 \&$ Jansson et al, 2008). Nota-se a presença de microabscessos, úlceras, hemorragia e necrose tecidual, com relativa metaplasia epitelial são encontradas em cortes histológicos corados por técnica de hematoxilina e eosina (HE) (Jansson et al, 2008). Segundo Martins et al (2006), relataram sucesso na visualização de M. ornithogaster em corte histológico de pró-ventrículo de mandarim (Taeniopygia guttata). Macrorhabidus ornithogaster tende a se acumular em áreas de pH alcalino, como a transição proventrículo e ventrículo (Son et al., 2004).

A técnica do ácido periódico de Schiff (PAS) constitui a mais comumente empregada na pesquisa de M. ornithogaster em cortes histológicos provenientes de casos de megabacteriose. Técnicas de coloração por impregnação de prata, frequentemente, empregadas em micologia, também são recomendadas (Gerlach, 2001, Son et al, 2004, Segabinazi et al, 2004 \& Flôres et al, 2005). O agente é identificado pela disposição paralela, aglomerada ou em paliçada, diretamente aderido à mucosa e/ou colonizando criptas produzidas na mesma (Segabinazi et al, $2004 \&$ Martins et al, 2006).

\subsection{Tratamento}

Antes que seja estabelecido o tratamento, alguns critérios devem ser levados em conta, para que medicamentos empregados não sejam desperdiçados e o dinheiro não seja gasto indiscriminadamente. Em primeiro lugar, a condição clínica dos animais avaliados é muito importante, isto é, se os animais apresentam sinais clínicos ou se são apenas reservatórios. É consenso entre a maioria dos autores que animais que expressam sinais clínicos compatíveis com megabacteriose, devem ser tratados. No entanto, isso não pode ser considerado para aqueles animais assintomáticos (Speer et al, 2004 \& Martins et al, 2006). Aves imaturas, ou seja, menores que quatro semanas, podem apresentar alta concentração de microrganismos nas fezes. Ainda não existem evidências de que aves adultas que tenham tido $M$. ornithogaster em alguma fase de suas vidas, desenvolvam algum tipo de imunidade específica contra esse agente, contudo, acredita-se que aves jovens colonizadas por $M$. ornithogaster se tornam negativas conforme amadurecem, entre as 16 e 24 semanas de idade (Speer et al, 2004).

Vários protocolos terapêuticos têm sido propostos para o tratamento da megabacteriose, ao longo dos últimos anos dedicados ao estudo da doença. Entre os princípios ativos atualmente empregados, destacamos a nistatina e anfotericina B, dois polienos que têm tropismo pelo ergosterol, interferindo, portanto, com a formação da membrana celular do microrganismo (Scullion \& Scullion, 2004, Speer et al, 2004, Son et al, 2004, Flôres et al, 2005 \& Martins et al, 2006). A dose recomendada de anfotericina B varia de 100-200 mg/kg de peso vivo, administrada por via oral a cada 12 horas, durante um período de cerca de 10-14 dias. Melhora considerável já pode ser notada entre a segunda ou quarta administração. Os autores confirmam que outro polieno, a nistatina apresenta efetividade no tratamento, especialmente, quando associada à anfotericina B (Scullion \& Scullion, 2004, Speer et al, 2004 \& Flôres et al, 2005). Vale salientar que aves que apresentem doença de base debilitante, ainda persistente, devem sempre receber tratamento de suporte adequado; que a expectativa de cura em relação ao tratamento 
de aves sintomáticas não é de 100\% e que os casos recidivantes são comuns (Cristensen et al, 1997, Speer et al, 2004 \& Bruno, 2016).

Existem trabalhos que apontam eficácia de fluconazol (5-100mg/kg, dependendo da espécie animal) e benzoato de sódio no tratamento da megabacteriose (Bruno, 2016). A associação do tratamento associado ao aumento do ph do trato gastrintestinal é aconselhável, uma vez que $M$. ornithogaster tem demonstrado preferência por meios mais alcalinos, além do que, a acidez favorece a absorção do fluconazol (Bruno, 2016). Isso pode ser obtido através da administração de ácidos orgânicos, como vinagre de maça, vinagre branco ou suco de cidra; ou pela administração de lactobacillus spp. (gerlach, 2001; son et al., 2004).

\subsection{Profilaxia}

O Brasil é referência mundial em biodiversidade de espécies de aves silvestres, além de ser um importante produtor de carne e derivados avícolas. A megabacteriose apresenta altos índices de morbidade e mortalidade em aves de inúmeras espécies, constituindo doença infecciosa aviária de considerável potencial de transmissão interespecífica (Gerlach, 2001, Scullion \& Scullion, 2004, Flôres et al, 2005, Marlier et al, 2006 \& Martins et al, 2006). É importante que o médico veterinário esteja atento às questões de biossegurança empregadas nas criações domésticas e comerciais sob sua responsabilidade e aos sinais clínicos que podem ser associados à doença. A quarentena de novos espécimes ou novos lotes que serão posteriormente introduzidos em populações já estabelecidas é imprescindível para o controle da disseminação de $M$. ornithogaster entre essas populações (Filippich, 2004, Speer et al, 2004, Phalen, 2005, Flôres et al, 2005 \& Martins et al, 2006).

A identificação laboratorial dos reservatórios de M. ornithogaster deve ser acompanhada de procedimentos higiênicos adequados, baseados na desinfecção periódica de todo o ambiente frequentado pelas aves, inclusive as gaiolas, evitando que as aves tenham contato com as fezes contaminadas (Speer et al, 2004, Phalen, 2005 \& Flôres et al, 2005). Existem pesquisadores que consideram M. ornithogaster como um patógeno oportunista, por isso, doenças concomitantes devem sempre ser controladas. A degradação do estado geral do paciente e/ou doenças de base capazes de produzir imunocomprometimento, tais como estresse, desnutrição, antibióticoterapia prolongada, doenças infecciosas e parasitárias, uso prolongado de corticosteróides constituem importantes fatores predisponentes para a megabacteriose (Anitinoff et al, 2004).

\section{Considerações Finais}

A literatura disponível é ainda bastante escassa. Novos trabalhos de pesquisa ainda são necessários para o esclarecimento de muitos aspectos da megabacteriose. Caso esses estudos comprovem a mobilidade apresentada por $M$. ornithogaster, como sugerem alguns autores, uma nova classificação taxonômica deverá ser adotada, estabelecendo a real identidade etiológica da doença, assim como já ocorreu anteriormente com outros patógenos de importância médica e veterinária, tais como Pythium incidiosum. Além disso, uma melhor caracterização de M. ornithogaster é necessária para que eventuais achados laboratoriais possam elucidar os pesquisadores a respeito dos nichos ecológicos dos quais esse microrganismo possa se valer, contribuindo enormemente para o progresso dos conhecimentos sobre a epidemiologia e diagnóstico dessa enfermidade. Finalmente, o emprego de novas drogas, assim como, protocolos terapêuticos, economicamente, mais acessíveis devem ser estimulados, trazendo benefícios tanto para os animais como para a indústria avícola mundial. 


\section{Referências}

Aguilar, R. F., Hernández-Divers, S. M., \& Hernández-Divers, S. J. (2005). Atlas de medicina, terapéutica y patología de animales exóticos (609. 9 AGUa). Andreatti Filho, R. L. (2007). Saúde aviária e doenças. Editora Roca.

Assis, A. C. B., \& Santos, B. M. (2001). Patogenicidade in vivo e in vitro de amostras de Escherichia coli de origem aviária. Brazilian Journal of Poultry Science, 3, 181-184.

AAI (Associação de Avicultura Industrial). Estrutiocultura brasileira em busca de crescimento. <https://www.aviculturaindustrial.com.br/imprensa/estrutiocultura-brasileira-em-busca-de-crescimento/20110325-131658-j915> Acesso: 20 abr 2016.

Baker, J. R. (1992). Megabacteriosis in exhibition budgerigars. The Veterinary Record, 131(1), 12-14.

Baker, J. R. (1996). Causes of mortality and morbidity in exhibition budgerigars in the United Kingdom. Veterinary record, 139(7), 156-162.

Baron, H. R., Stevenson, B. C., \& Phalen, D. N. (2021). Comparison of In-Clinic Diagnostic Testing Methods for Macrorhabdus ornithogaster. Journal of Avian Medicine and Surgery, 35(1), 37-44.

Benez, S. M. (1998). Aves criação, clínica, teoria e prática. In Aves criação, clínica, teoria e prática (pp. 468-468).

Bentubo, H. D. L. (2008). Leveduras do gênero Trichosporon: aspectos ecológicos, caracterização laboratorial, fatores associados à virulência e suscetibilidade a antifúngicos (Doctoral dissertation, Universidade de São Paulo).

Bruno, D. B. (2016). Métodos de diagnóstico e tratamento para megabacteriose em aves selvagens: Revisão sistemática.

Cambuí, Y. R. S., \& Natali, M. R. M. (2015). Doenças inflamatórias intestinais: revisão narrativa da literatura. Revista da Faculdade de Ciências Médicas de Sorocaba, 17(3), 116-119.

Christensen, N. H., Hunter, J. E. B., \& Alley, M. R. (1997). Megabacteriosis in a flock of budgerigars. New Zealand veterinary journal, 45(5), $196-198$.

Cook, S. (2000). Role of megabacteria in mammals [Letter]. Veterinary Records, 146, 444.

De Andrade, M. A. (1997). A vida das aves: introdução à biologia e conservação. Fundação Acangaú: Líttera.

De Araujo Cavalcante Filho, L., dos Santos Nascimento, J. C., da Fonseca Filho, L. B., Amorim, M. J. A. A. L., Barros, M. R., \& de Moura, R. T. D. (2017). Megabacteriose em Calopsita (Nymphicus hollandicus). PUBVET, 11, 646-743.

De Hoog, G. S. (1996). Risk assessment of fungi reported from humans and animals. Mycoses, 39(11-12), 407-417.

De Queirós, T. S., de Carvalho, P. R., \& Pita, M. C. G. (2011). Megabacteriose: Macrorhabdus ornithogasterem aves-Revisão. PUBVET, 5, Art-1079.

Dorrestein, G. M., Zwart, P., \& Buitelaar, M. N. (1980). Problems arising from disease during the periods of breeding and rearing canaries and other aviary birds (author's transl). Tijdschrift voor diergeneeskunde, 105(13), 535-543.

Ferenhof, H. A., \& Fernandes, R. F. (2016). Desmistificando a revisão de literatura como base para redação científica: método SSF. Revista ACB, 21(3), 550563.

Filippich, L. J., \& Hendrikz, J. K. (1998). Prevalence of megabacteria in budgerigar colonies. Australian veterinary journal, 76(2), 92-95.

Gerlach, H. (2001). Megabacteriosis. Seminars in avian and exotic pet medicine. 10: 12-19.

Gonçalves, J. R. (2019). Como escrever um Artigo de Revisão de Literatura. Revista JRG de Estudos Acadêmicos, 2(5), 29-55.

Gottdenker, N. L., Walsh, T., Vargas, H., Merkel, J., Jiménez, G. U., Miller, R. E., Dailey, M., \& Parker, P. G. (2005). Assessing the risks of introduced chickens and their pathogens to native birds in the Galápagos Archipelago. Biological Conservation, 126(3), 429-439.

Hannafusa, Y., Bradley, A., Tomaszewski, E. E., Libal, M. C., \& Phalen, D. N. (2007). Growth and metabolic characterization of Macrorhabdus ornithogaster. Journal of veterinary diagnostic investigation, 19(3), 256-265.

Harrison, G. J., Lightfoot, T. (2006). Clinical Avian Medicine. Palm Beach: Spix Publishing.

Henderson, G. M., Gulland, F. M., \& Hawkey, C. M. (1988). Haematological findings in budgerigars with megabacterium and Trichomonas infections associated with'going light'. The Veterinary Record, 123(19), 492-494.

Hofling, E., Camargo, H. F. A. (2002). Aves No Campus. São Paulo: Edusp.

Huchzermeyer, F. W., Henton, M. M., \& Keffen, R. H. (1993). High mortality associated with megabacteriosis of proventriculus and gizzard in ostrich chicks. The Veterinary Record, 133(6), 143-144.

Huchzermeyer, F., Henton, M. (2000). Megabacteria in mammals [letter]. Veterinary Records, 146: 768.

IBAMA (Instituto Brasileiro do Meio Ambiente e dos Recursos Naturais Renováveis). Diagnóstico da criação de animais silvestres no Brasil. <https://www.gov.br/ibama/pt-br/centrais-de-conteudo/2019-ibama-diagnostico-criacao-animais-silvestes-brasil-pdf/view>.

Ibiapina, C. D. C., Costa, G. A., \& Faria, A. C. (2005). Influenza A aviária (H5N1): a gripe do frango. Jornal Brasileiro de Pneumologia, 31 , $436-444$. 
Jansson, D. S., Bröjer, C., Mattsson, R., Feinstein, R., Mörner, T., \& Segerstad, C. H. (2008). Mycotic proventriculitis in gray partridges (Perdix perdix) on two game bird farms. Journal of Zoo and Wildlife Medicine, 39(3), 428-437.

Lacaz, C. D. S., Porto, E., Martins, J. E. C., Heins-Vaccari, E. M., \& Takahashi de Melo, N. (2002). Tratado de micologia médica.

Lima Jr, J. S., Pinto, D., Carrasco, L., Carrasco, F., \& Meireles, M. (2012). Incidência de fungos na produção de pintos de corte de um dia de idade. Revista Brasileira de Agrociência, 7(1).

Marinho, M., Meireles, M. V., \& Souza, A. V. G. (2004). Determinação da microflora do trato gastrintestinal de avestruzes (Struthio camelus) criados na região noroeste do estado de São Paulo, submetidas à necropsia. Arquivos do Instituto Biológico, 71(3), 267-271.

Marlier, D., Leroy, C., Sturbois, M., Delleur, V., Poulipoulis, A., \& Vindevogel, H. (2006). Increasing incidence of megabacteriosis in canaries (Serinus canarius domesticus). The Veterinary Journal, 172(3), 549-552.

Martins, N. R. S., Horta, A. C., Siqueira, A. M., Lopes, S. Q., Resende, J. S., Jorge, M. A., Assis, R. A., Martins, N. A., Fernandes, A. A., Barrios, P. R., Costa, T. J. R., \& Guimarães, L. M. C. (2006). Macrorhabdus ornithogaster in ostrich, rhea, canary, zebra finch, free range chicken, turkey, guinea-fowl, columbina pigeon, toucan, chuckar partridge and experimental infection in chicken, japanese quail and mice. Arquivo Brasileiro de Medicina Veterinária e Zootecnia, 58(3), 291-298.

MMA (Ministério do Meio Ambiente). Vertebrados. Avaliação do estado do conhecimento da diversidade biológica do brasil. https://antigo.mma.gov.br/estruturas/chm/_arquivos/verteb.pdf>.

Moore, R. P., Snowden, K. F., \& Phalen, D. N. (2001). A method of preventing transmission of so-called "megabacteria" in budgerigars (Melopsittacus undulatus). Journal of Avian Medicine and Surgery, 15(4), 283-287.

Moreira, W. (2004). Revisão de literatura e desenvolvimento científico: conceitos e estratégias para confecção. Janus, 1(1).

Moreira, A. D. C. (2019). Megabacteriose (Macrorhabdus ornithogaster): revisão de literatura, relato de caso e elaboração de folder de orientação.

Nascimento, M., Alves E. (2007). A problemática do tráfico: educação e conscientização ambiental. Pallotti.

Phalen, D. N., \& Moore, R. P. (2003). Experimental infection of white-leghorn cockerels with Macrorhabdos ornithogaster (Megabacterium). Avian diseases, 47(2), 254-260.

Phalen, D. (2005). Diagnosis and management of Macrorhabdus ornithogaster (formerly megabacteria). Veterinary Clinics: Exotic Animal Practice, 8(2), 299306.

Pennycott, T. W., Duncan, G., \& Venugopal, K. (2003). Marek's disease, candidiasis and megabacteriosis in a flock of chickens (Gallus gallus domesticus) and Japanese quail (Coturnix japonka). Veterinary record, 153(10), 293-297.

Ravelhofer-Rotheneder, K., Engelhardt, H., Wolf, O., Amann, R., Breuer, W., \& Kosters, J. (2000). Taxonomic classification of" megabacteria"-isolates originating from budgerigars (Melopsittacus undulatus Shaw, 1805). Tierarztliche Praxis Ausgabe Kleintiere Heimtiere, 28(6), 415-420.

Revolledo, L. \& Piantino-Ferreira, A. J. (2009). Patologia Aviária. Manole.

Ritchie, B. W., Hsarrison, G. J., Zantop, D., \& Harrison, L. R. (1997). Avian medicine: principles and application, abridged edition. Idaho Falls, ID: Wingers Publishing.

Robino, P., Ferrocino, I., Rossi, G., Dogliero, A., Alessandria, V., Grosso, L., Galosi, L., Tramuta, C., Cocolin, L., \& Nebbia, P. (2019). Changes in gut bacterial communities in canaries infected by Macrorhabdus ornithogaster. Avian Pathology, 48(2), 111-120.

Scanlan, C. M., \& Graham, D. L. (1990). Characterization of a gram-positive bacterium from the proventriculus of budgerigars (Melopsittacus undulatus). Avian Diseases, 779-786.

Scullion, F. T., \& Scullion, M. G. (2004). Successful treatment of megabacteriosis in a canary (Serinus canaria) with nystatin. The veterinary record, 155(17), $528-529$.

Segabinazi, S. D., Flôres, M. L., Kommers, G. D., Barcelos, A. D. S., Veit, D. C., \& Eltz, R. D. (2004). Megabacteriose em emas (Rhea americana) no Estado do Rio Grande do Sul, Brasil. Ciência Rural, 34, 959-960.

Segabinase, S. D. \& Flôres, M. L. (2005). Surto de megabacteriose em canários-belga (Serinus canaria) em um criatório no estado do Rio Grande do Sul: relato de caso. Clínica Veterinária, 54, 24-26.

Shenep, J. L., English, B. K., Kaufman, L., Pearson, T. A., Thompson, J. W., Kaufman, R. A., Frisch, G., \& Rinaldi, M. G. (1998). Successful medical therapy for deeply invasive facial infection due to Pythium insidiosum in a child. Clinical infectious diseases, 27(6), 1388-1393.

Silva, E. N. D., \& Duarte, A. (2002). Salmonella Enteritidis em aves: retrospectiva no Brasil. Brazilian Journal of Poultry Science, 4, 85-100.

Silva, J. C. R. (2007). Tratado de animais selvagens-medicina veterinária. Editora Roca.

Simpson, V. R. (1992). Megabacteriosis in exhibition budgerigars. Veterinary record (United Kingdom).

Son, T. T., Wilson, G. H., \& Latimer, K. S. (2004). Clinical and pathological features of megabacteriosis (Macrorhabdus ornithogaster) in birds. Veterinary clinical pathology clerkship program. 
Research, Society and Development, v. 11, n. 1, e20211125146, 2022

(CC BY 4.0) | ISSN 2525-3409 | DOI: http://dx.doi.org/10.33448/rsd-v11i1.25146

Speer, B., Phalen, D. N., Powers, L. V., Filippich, L. J., \& Antinoff, N. (2004). Diagnosis and treatment options for megabacteria (Macrorhabdus ornithogaster). Journal of Avian Medicine and Surgery, 18(3), 189-195.

Tomaszewski, E. K., Logan, K. S., Snowden, K. F., Kurtzman, C. P., \& Phalen, D. N. (2003). Phylogenetic analysis identifies the 'megabacterium'of birds as a novel anamorphic ascomycetous yeast, Macrorhabdus ornithogaster gen. nov., sp. nov. International journal of systematic and evolutionary microbiology, 53(4), 1201-1205.

Tonelli, A. (1993). Megabacteriosis in exhibition budgerigars. Veterinary record (United Kingdom).

UBA-Abef (União Brasileira De Avicultura e Exportadores de Frango). Relatório anual da UBA 2009. <http://www.uba.org.br/index.htm>.

UNESP. Faculdade de Ciências Agronômicas. Biblioteca Prof. Paulo de Carvalho Mattos. (2015). Tipos de revisão de literatura. Botucatu.

Van Herck, H., Duijser, T., Zwart, P., Dorrestein, G. M., Buitelaar, M., \& Van Der Hage, M. H. (1984). A bacterial proventriculitis in canaries (Serinus canaria). Avian Pathology, 13(3), 561-572.

Werther, K., Schocken-Iturrino, R. P., Verona, C. E. S., \& Barros, L. S. S. (2000). Megabacteriosis occurrence in budgerigars, canaries and lovebirds in Ribeirão Preto region-Sao Paulo state-Brazil. Brazilian Journal of Poultry Science, 2(2), 183-187. 